\title{
Estimate of severe autosomal recessive limb-girdle muscular dystrophy (LGMD2C, LGMD2D) among sporadic muscular dystrophy males: a study of 415 familes
}

\author{
I Stec, W Kress, G Meng, B Müller, C R Müller, T Grimm
}

\begin{abstract}
Ninety-five percent of cases of severe muscular dystrophy with early childhood onset result from mutations in the dystrophin region of the human $X$ chromosome (DMD, McKusick 310200), whereas $5 \%$ are thought to result from mutations in autosomal genes. We examined a total of 415 families with at least one living patient whose clinical features suggested DMD. Based on formal genetics, haplotype analysis, and dystrophin determinations, we estimate that one in eight $(11 \cdot 8 \%)$ sporadic male patients carries autosomal rather than $X$ chromosomal mutations.
\end{abstract}

( $(\mathcal{M}$ Med Genet 1995;32:930-933)

Institute of Human Genetics, Biocentre/Hubland University of

Würzburg,

D-97074 Würzburg,

Germany

I Stec

W Kress

G Meng

C R Müller

T Grimm

Bernhard-NochtInstitut, Department of Molecular Genetics, Hamburg, Germany B Müller

Correspondence to: Dr Stec.

Received 12 June 1995 Revised version accepted fo publication 15 August 1995
Duchenne muscular dystrophy (DMD) is one of the most common monogenic disorders; it is caused by $\mathrm{X}$ linked recessive mutations at the dystrophin locus on band Xp21. ${ }^{1-5}$ The autosomal recessive forms of muscular dystrophy (Duchenne-like autosomal recessive muscular dystrophy, McKusick $253700,{ }^{6}$ LGMD2 types A, B, C, and D (limb-girdle muscular dystrophy types $2 \mathrm{~A}, \mathrm{~B}, \mathrm{C}$, and D), ${ }^{7}$ McKusick 253600, 253601, 253700, 600506, $600119)^{6}$ are heterogeneous since gene assignments have been made to different loci: $15 \mathrm{q}$ (LGMD2A), ${ }^{8}$ 2p13.3 (LGMD2B), ${ }^{9}$ 13q12(LGMD2C, previously SCARMD1), ${ }^{1011}$ and 17q12-q21.33 (LGMD2D, previously SCARMD2). ${ }^{1213}$ The autosomal recessive childhood form of SCARMD (severe child-

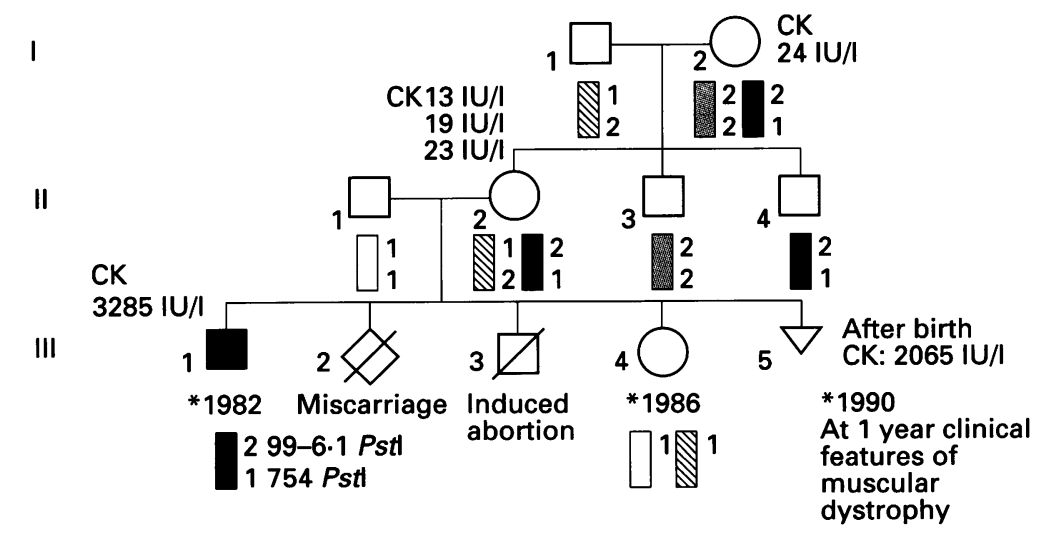

Figure 1 Pedigree of family $A$.

hood autosomal recessive muscular dystrophy) has recently been classified as LGMD2C and LGMD2D ${ }^{7}$ and this nomenclature will be used throughout this paper.

LGMD2 is characterised by normal dystrophin, ${ }^{14}$ whereas the muscle biopsies of typical $\mathrm{X}$ linked DMD patients show virtually no dystrophin. In autosomal recessive LGMD, a deficiency of adhalin $(50 \mathrm{kDa}$ dystrophin associated glycoprotein ( $50 \mathrm{kDa} \mathrm{DAG})$ ) has been shown either as a primary gene defect in the adhalin gene on chromosome $17 \mathrm{q}^{1213}$ or as a secondary event to a separate gene on chromosome 13q. ${ }^{1011}$

\section{Case reports}

Two pedigrees were chosen to illustrate our reasoning in favour of LGMD2C/LGMD2D in families presenting with single affected males. In family A (fig 1 ), III 11 was suspected of having DMD because of his clinical findings (pseudoathletic body, muscle weakness, spinal lordosis, calf pseudohypertrophy, waddling gait, discrete Gower's sign) and high serum creatine kinase (CK) levels. No deletion in $\mathrm{Xp} 21$ was detectable. Indirect genetic diagnosis showed that he had inherited the grandmaternal (I-2) alleles from his mother (II-2). The two healthy uncles (II.3 and II.4) inherited different haplotypes from the patient's grandmother. This leads to the conclusion that the grandmother cannot be a carrier for DMD. The proband (III-1) could either be the result of a new mutation in one of his mother's germ cells or in one of his grandmother's germ cells. In 1989 the mother of the proband became pregnant again. Prenatal diagnosis was carried out and the fetus showed a female karyotype. To confirm his diagnosis, the proband underwent muscle biopsy. Dystrophin analysis yielded dystrophin of normal size and abundance. Therefore the mother was counselled that the risk for her female fetus being affected was $25 \%$; the mother decided to continue pregnancy. After the birth the newborn daughter had extremely high CK levels (2065 IU/1) and at the age of 1 year she showed clinical signs of muscular dystrophy like her brother. Thus, autosomal recessive muscular dystrophy is the most likely explanation in this family.

The first son (III-1) in family B (fig 2) was diagnosed as having DMD because of his clinical manifestations (muscle weakness, Gowers' sign, calf pseudohypertrophy, spinal lordosis) 
1

II

III

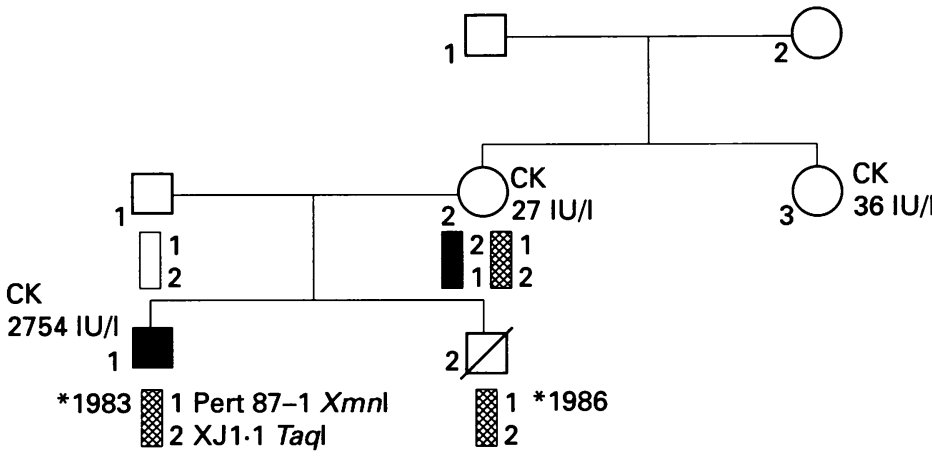

Figure 2 Pedigree of family $B$.

\section{Evaluation of families}

Between 1982 and 1995, 415 families with at least one living patient with clinical signs of DMD were referred to our laboratory. All patients were screened for deletions either with the $14 \mathrm{~kb}$ cDNA of human dystrophin ${ }^{5}$ (until 1990 ) or with multiplex PCR using 18 (in part 19) exon specific primers ${ }^{1516}$ (from 1990 onwards). These assays detect about $98 \%$ of all deletions within the Duchenne gene region. If we did not find a deletion in the latter cases but a completely negative dystrophin status, we performed further deletion screening with cDNA. In 256 families a deletion, duplication, or point mutation was detected by DNA analysis of the DMD gene. Thirty-one of the remaining 159 families showed typical X linked inheritance with one or more affected sons in at least two generations. The remaining 128 families consisted of sporadic/sib cases in which autosomal recessive inheritance had to be taken into consideration. Assuming a prior probability of $5 \%$ ( 21 of 415 families) for autosomal recessive inheritance among all families with a clinical diagnosis of DMD, ${ }^{17} 21$ of these 128

\section{DMD}

Duchenne muscular
dystrophy
Severe LGMD2

Severe (autosomal recessive) limb-girdle muscular dystrophy

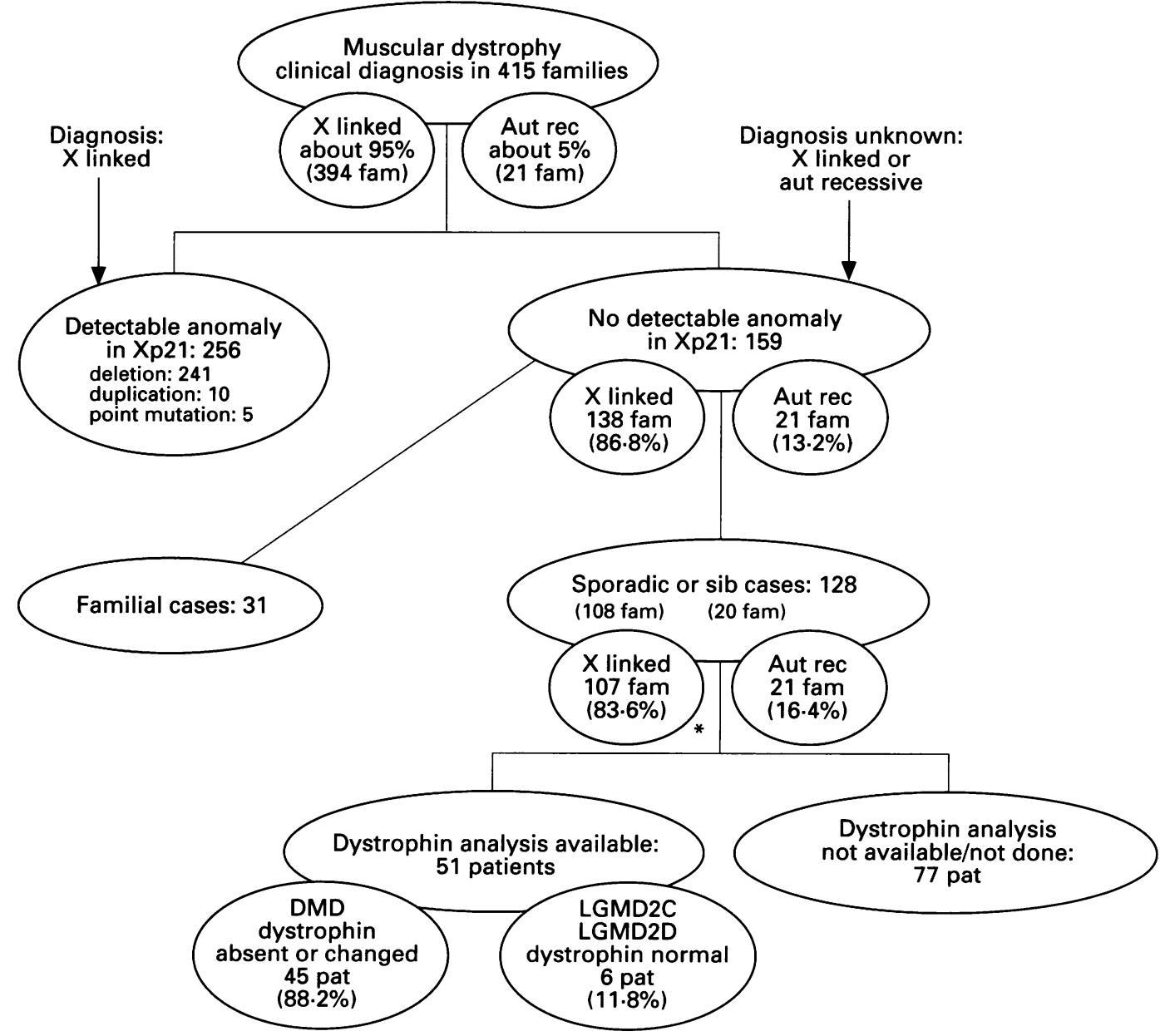

Figure 3 Estimation of the proportion of severe autosomal recessive limb-girdle muscular dystrophy (LGMD2C/ LGMD2D) among 415 muscular dystrophy families. *The estimate of $83.6 \% \mathrm{X}$ linked of these sporadic/sib cases is an arithmetical derivative from the starting 5\%, after having removed the familial cases and those with detectable Xp21 mutations. 
families $(16 \cdot 4 \%)$ could be the result of autosomal recessive inheritance (fig 3). For 51 patients of the 128 families, dystrophin analysis of muscle biopsy was available in order to determine the presence or absence of dystrophin (western blot/immunohistochemical analysis). Forty-five patients lacked dystrophin, but six patients showed dystrophin of normal size and abundance. This yields a cumulative risk of $11 \cdot 8 \%$ that sporadic/sib cases are affected by LGMD2C/LGMD2D. In 1991, a study by Vainzof $e t a l^{18}$ estimated that about 8 to $12 \%$ of males with a clinical diagnosis of DMD, in whom $\mathrm{X}$ linked inheritance had been excluded, are thought to be affected by autosomal recessive muscular dystrophy.

The flow chart shown in fig 3 summarises the course and the results of our investigation.

\section{Discussion}

For both DMD and the milder form, BMD (Becker muscular dystrophy), an autosomal recessively inherited phenocopy is known. Two important aspects should be taken into account in genetic counselling of families with a sporadic/sib DMD case without a detectable anomaly in the dystrophin gene.

(1) If one assumes that about $5 \%$ of all childhood MD cases are caused by autosomal recessive mutations, ${ }^{17} 16 \cdot 4 \%$ of all sporadic/sib cases without a detectable mutation are expected to show the autosomal recessive mode of inheritance. Our own dystrophin data showed normal dystrophin in six of $51(11 \cdot 8 \%)$ patients. A realistic estimate of the proportion of autosomal recessive muscular dystrophy therefore might lie between $11.8 \%$ and $16.4 \%$. Sibs of both sexes of these affected males would have a probability of 0.25 of being affected.

(2) With regard to sisters of affected males it is important to know whether the defect follows autosomal or X linked inheritance, since the risk for affected sons of these sisters differs

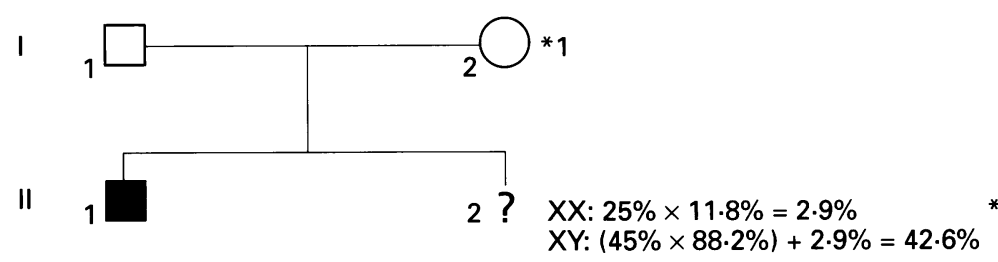

Figure 4 Calculation of the risk for II $\cdot 2$ being affected with $X$ linked or autosomal recessive muscular dystrophy. ${ }^{*} 1$. The risk for the mother $I \cdot 2$ in our model pedigree being heterozygous for DMD is $66.7 \%$, if the mutation in the affected son is unknown. If the patient has an undetectable mutation (point mutation) her risk of being heterozygous increases to about $90 \% .^{19} * 2$. 6 of $51=11 \cdot 8 \%$; 45 of $51=88 \cdot 2 \%$.

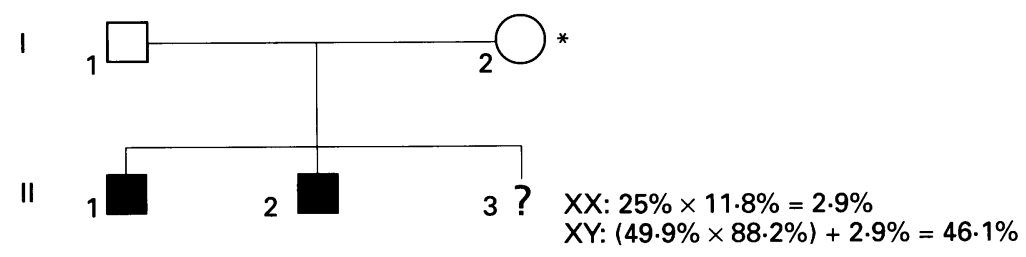

Figure 5 Calculation of the risk for II 3 being affected with $X$ linked or autosomal recessive muscular dystrophy. ${ }^{*}$ The risk for the mother I.2 in the model pedigree being heterozygous for DMD increases to $99.9 \%$ because of her two affected sons; see also the legend to fig 4. greatly. If the sister is a carrier of $\mathrm{X}$ linked DMD, $50 \%$ of her sons would be affected. If the disease is autosomal recessive, the risk for her children would be minimal. For the determination of genetic risk and planning a preventive strategy in DMD families, it is essential to distinguish between $\mathrm{X}$ linked $\mathrm{DMD}$ and severe LGMD2C/LGMD2D. If there is no detectable mutation in the region of Xp21 in sporadic/sib cases we strongly recommend taking a muscle biopsy for dystrophin analysis.

A quite frequent situation in clinical practice is the lack of dystrophin determination in sporadic cases without evidence for a detectable structural anomaly in the dystrophin gene. In such cases, the following considerations apply (fig 4).

In the situation illustrated in fig 4 , female offspring would carry a risk of $25 \%$ (a priori probability for autosomal recessive inheritance) multiplied by $11.8 \%$ (posterior probability for autosomal recessive inheritance), that is, $2.9 \%$. Male offspring would carry a risk of $45 \%$ (X linked inheritance, assuming that the mother has a probability of $90 \%$ of being heterozygous) multiplied by $88 \cdot 2 \%$ (who were the $45 \mathrm{dy}-$ strophin negative patients in our investigation, meaning $X$ linked inheritance) plus $2.9 \%$ (the mother and the father are heterozygous for autosomal recessive muscular dystrophy), that is, $42 \cdot 6 \%$.

In the case that there are two affected male sibs (fig 5), the risk for an affected son would amount to around $46 \%$, while the risk for an affected girl, assuming autosomal recessive inheritance, does not decrease significantly.

So far there are no reliable published data about the distribution of CK values in heterozygotes in autosomal recessive LGMD. Therefore it would seem to be important to determine CK levels of all mothers and fathers of a sporadic/sib DMD case, in whom no detectable anomaly in $\mathrm{Xp} 21$ or dystrophin in muscle biopsy is found.

1 Murray JM, Davies KE, Harper PS, Meredith L, Müller $\mathrm{CR}$, Williamson R. Linkage relationship of a cloned DNA sequence on the short arm of the $\mathrm{X}$ chromosome to Duchenne muscular dystrophy. Nature 1982;300:69-71.

2 Francke U, Ochs HD, de Martinville B, et al. Minor Xp21 chromosome deletion in a male associated with expression of Duchenne muscular dystrophy, chronic granulomatous disease, retinitis pigmentosa and McLeod syndrome. $\mathrm{Am}$ f Hum Genet 1985;37:250-67.

3 Monaco AP, Neve R, Colletti-Feener R, Bertelson CJ, Kurnit M, Kunkel LM. Isolation of candidate cDNAs for portions of the Duchenne muscular dystrophy gene. Nature portions of the Duch

4 Burghes AHM, Logan C, Hu K, Belfall B, Worton RG, Ray PN. A cDNA clone from the Duchenne/Becker muscular dystrophin gene. Nature 1987;328:434-7.

5 Koenig M, Hoffmann E, Bertelson CJ, Monaco A, Feener C, Kunkel LM. Complete cloning of the Duchenne muscular dystrophy DMD CDNA and preliminary genomic organization of the DMD gene in formal and affected individuals. Cell 1987;50:509-17.

$6 \mathrm{McKusick}$ VA, Mendelian inheritance in man (GDB-OMIM). Catalogs of autosomal dominant, autosomal recessive, and $X$-linked phenotypes. 253700, 253600, 235601, 600506, 600119. Baltimore: Johns Hopkins University Press, 1995.

7 Bushby KMD, Beckmann JS. 30th and 31st ENMC workshops on the limb-girdle muscular dystrophies-proposal for a new nomenclature. Neuromusc Dis 1995;5:337-43.

8 Beckmann JS, Richard I, Hillaire D, et al. A gene for limbgirdle muscular dystrophy maps to chromosome 15 by linkage. C R Acad Sci Paris 1991;312:141-8.

9 Bashir R, Strachan T, Keers S, et al. A gene for autosomal recessive limb-girdle muscular dystrophy maps to chromosome 2p. Hum Mol Genet 1994;3:455-7.

10 Ben Othmane K, Ben Hamida M, Pericak Vance MA, et al. Linkage of Tunisian autosomal recessive Duchennelike muscular dystrophy to the pericentromeric region of chromosome 13q. Nature Genet 1992;2:315-17. 
11 Azibi K, Bachner L, Beckmann JS, et al. Severe childhood autosomal recessive muscular dystrophy with the deficiency of the $50 \mathrm{kDa}$ dystrophin-associated glycoprotein maps to chromosome 13q12. Hum Mol Genet 1993;2:

12 Roberds SL, Leturocq F, Allamand V, et al. Missense mutations in the adhalin gene linked to autosomal recessive muscular dystrophy. Cell 1994;78:625-33.

13 Piccolo F, Roberds SL, Jeanpierre M, et al. Primary adhalinopathy: a common cause of autosomal recessive muscular dystrophy of variable severity. Nature Genet 1995 10:213-15.

14 Ben Jelloun-Dellagi S, Chaffey P, Hentati F, et al. Presence of normal dystrophin in Tunisian severe childhood autosomal recessive muscular dystrophy. Neurology 1990;40: 1903.

15 Chamberlain JS, Gibbs RA, Ranier JE, Nguyen PN, Caskey CT. Deletion screening of the Duchenne muscular dys- trophy locus via multiplex DNA amplification. Nucleic Acids Res 1988;16:11141-56.

16 Begs AH, Kenig M Boyce FM, Kunkel LM. Detection Beggs AH, Koenig M, Boyce FM, Kunkel LM. Detection
of $98 \%$ of DMD/BMD gene deletions by polymerase chain reaction. Hum Genet 1990;86:45-8.

17 Emery AEH. Population frequencies of inherited neuromuscular diseases - a world survey. Neuromusc Dis 1991; 1:19-29.

18 Vainzof M, Pavanello RCM, Pavanello-Filho I, et al. Screening of male patients with autosomal recessive Duchenne muscular dystrophy through dystrophin and DNA studies. Am $\mathcal{F}$ Med Genet 1991;39:38-41.

19 Grimm T, Meng G, Liechti-Gallati S, Bettecken T, Müller $\mathrm{CR}$, Müller B. On the origin of deletions and point mutations in Duchenne muscular dystrophy; most deletions arise in oogenesis and most point mutations result from events in spermatogenesis. f Med Genet 1994;31: 183-6. 